\title{
RECOVERY OF MORE THAN 10 YEARS-DRYING MONASCUS CULTURES AND ITS PURIFICATION METHODS FROM FUNGAL AND BACTERIAL CONTAMINATION
}

\author{
NANDANG SUHARNA \\ Microbiology Division, Research Center for Biology, Indonesian Institute of Sciences \\ (LIPI), Cibinong, Jakarta, Indonesia
}

\begin{abstract}
This study was carried out to understand the recovery capability of more than 10 yearsdrying Monascus cultures. A new simple purification technique from fungal contamination using ethanol-soaking treatment was also reported as a part of this study. The result showed that all drying cultures were recovered well and retained their characters such as good growth, pigmentation and production of fruit bodies (ascomata), sexual spores (ascospores) and asexual spores. Several cultures showed its good growth in $20 \%$ ethanol medium. This study also reported successful purification of cultures from fungal contamination using ethanol-soaking treatment. This self-drying method, therefore, could be suggested as a good long-term preservation method for Monascus cultures. Moreover, purification method from fungal contamination soaked in ethanol $70 \%$ or $95 \%$ was successfully effective.
\end{abstract}

Key words: recovery, preservation, Monascus, drying, purification

\section{INTRODUCTION}

Monascus becomes recently popular as this fungus is used in food, specially Chinese red rice (angkak), red wine, rice wine, kaoliang beer, soya cheese and pigment, food colorant in Asia, mainly China, Philipines, Japan, Thailand and Indonesia (Steinkraus 1983). The major mold that plays this important role is $M$. purpureus. This fungus is mainly used in the production of angkak. This product mostly is known by its value as food or drink colorant since it can be used as an alternative for synthetic chemical based on its health concern. Monascus purpureus is also known as a producer of monacolin, a statin substance which can inhibit 3-Hydroxyi-3-methylglutaryl Coenzyme A (HMG-CoA) reductase in cholesterol biosynthesis (Endo 1979). Hence, monacolin production by this fungus is being extensively studied recently.

Corresponding author: nsuharna@yahoo.com 
Accordingly, on account of its highly benefits, maintenance and preservation of living Monascus cultures become extremely important so as to ensure its continuous use without risk of loss of its capability.

Currently, three primary methods of culture preservation are already known such as continuous growth, drying, and freezing. Continuous growth methods, in which cultures are grown on agar medium, generally are used for short-term storage. Such cultures are stored at temperatures of $5{ }^{\circ} \mathrm{C}-20{ }^{\circ} \mathrm{C}$, or they may be frozen to increase the interval between subcultures. The methods are simple and inexpensive because specialized equipment is not required (Smith 1993; Smith and Onion 1994; Nakasone et al. 2004).

In short-term storage, routine maintenance is usually not preferable, since it is laborious and has higher risk of loss of capability due to frequent transfer. Whilst, longterm storage much reduces transfer frequency and risk loss of capability. Therefore, the long-term storage will supply stock culture more safely with good quality.

Drying is the most useful method of preservation for cultures that produce spores or other resting structures. Drying methods are technically simple and also do not require expensive equipment (Smith 1993; Smith and Onion 1994; Nakasone 2004).

Freezing methods, including cryopreservation, are versatile and widely applicable. With or without cryoprotectants, most fungi can be preserved in liquid nitrogen or in standard home freezers. With freeze-drying, or lyophilization, the fungal cultures are frozen and subsequently dried under vacuum condition. The method is highly successful with cultures that produce mitospores. Freeze-drying and freezing below $-135^{\circ} \mathrm{C}$ are excellent methods for permanent preservation, and we highly recommend them. However, both methods require specialized and expensive equipment, as described in the next section. The choice of preservation method depends on the species concerned, the resources available and the goal of the project (Nakasone et al. 2004). We experienced with yearly storage of Monascus cultures preserved by grown on agar slant but then let dry naturally at room temperature. These cultures were tested for its recovery from years of incubation period. Preservation of Monascus culture using liquid drying started last year. However, our findings facilitate many things including handling of the microorganism.

The objective of this study is to know the recovery of Monascus cultures after drying for more than 10 years. This study also covered purification of drying Monascus cultures from microbial contamination. In this study, we also report our experience with purification of Monascus cultures from fungal contamination besides bacterial contamination. This report also covers a new simple method to purify Monascus cultures from fungal contamination. 


\title{
MATERIALS AND METHODS
}

\begin{abstract}
Monascus Strains
Seventeen strains of Monascus were used in this study (Table 1). These strains were preserved on slope agar and underwent drying during storage at room temperature for 10 years. Monascus cultures are maintained on Taoge (germinates of Phaseolus radiatus L.) Extract Agar 6\% (TA) slope at room temperature. TA medium preparation referred to Saono et al. (1969). This medium contained extract of germinating beans (Phaseolus radiatus L.), $6 \%$ sucrose and 15\% agar Bacto.
\end{abstract}

\section{Cultivation medium}

Media used for cultivation was malt extract agar (MEA) 2\% (Difco Ltd.) which composed of malt extract (2\%), peptone (10\%), glucose (10\%) and agar Bacto (15\%). Water Agar (WA) media used for cultivation of bacterial-contaminated culture of Monascus contained agar Bacto (15\%) and tap water; and ethanol liquid medium which was composed of ethanol 20\%, peptone 10\%, glucose 20\% and yeast extract 20\% (PGY ethanol 20\%) were used for cultivation in high concentration of alcohol.

\section{Water soaking treatment prior to re-cultivation of drying Monascus cultures}

Water soaking treatment is to soak dry cultures in TA medium by adding sterile distilled water three hours before re-cultivated on a new fresh TA medium.

\section{Recultivation of drying Monascus cultures}

Re-cultivation was carried out by transferring a small part of culture after treated by water soaking treatment on to MEA $2 \%$ plate. This plate is then incubated at room temperature.

\section{Purification from bacterial contamination}

Cultivation on Water Agar (WA) medium is very effective method to separate fungal colony from bacteria (Watanabe 2004). Therefore, this method was applied to purify Monascus culture from bacterial contamination. Before cultivation the contaminated culture was pre-treated by soaking in distilled water for three hours in order to soften and to re-hydrate the agar. Subsequently, a small part of the culture was removed and transferred into WA medium. After few days of incubation, the separation of fungi and bacteria can be observed. Isolation of Monascus colony free from bacterial colony was carried out and Monascus culture was re-cultivated onto a new fresh MEA $2 \%$ medium. 


\section{Purification from fungal contamination by ethanol soaking treatment}

To eliminate fungal contamination, a small part of the contaminated dry culture was soaked into ethanol $70 \%$ or $95 \%$ for one minute prior to cultivation on MEA $2 \%$. Incubation was done at room temperature. After three days incubation period, Monascus culture which was free from the fungal contaminant was transferred under aseptic condition to a new fresh medium.

\section{The effect of one minute-ethanol soaking treatment on Monascus growth}

The effect of one minute-ethanol-soaking treatment on Monascus growth was studied. Each sample of 14 drying Monascus cultures was soaked into ethanol before cultivation in agar medium. Prior to this treatment, the sample was soaked in water for three hours for re-hydration and to soften the agar so as to facilitate the fungus to grow. The cultures were then ready to be soaked in ethanol for one minute before cultivation on new fresh agar medium without rinsing using water.

\section{Observation on retained important characters of Monascus}

a. Observation on colony growth was determined by its growth intensity as + (good growth) or - (poor growth).

b. Observation on pigmentation is carried out by observing the occurrence of pigmentation visually.

c. Production of cleistothecium (ascomata/fruit bodies), ascospores (sexual/generative spore) and aleurispores (asexual/vegetative spore). After making slide preparation, microscopic observation was carried out and each production determined as + (good production) or - (no or poor production).

d. Growth in $20 \%$ ethanol medium. This is a test to know its growth capability of Monascus strains in high concentration of ethanol medium.

Table 1. List of Monascus collection maintained on slope agar that underwent drying during ten yearsstorage.

\begin{tabular}{cccc}
\hline Strain Code & Fungus Name & $\begin{array}{c}\text { Year Cultured } \\
\text { \& Stored }\end{array}$ & Source of Strains \\
\hline A70.1.2 & Monascus sp. & 1994 & Shrimp specimen preserved in ethanol \\
COEL & Monascus sp. & 1994 & Coelenterata specimen preserved in ethanol \\
KA15.1(I) & Monascus sp. & 1994 & Shrimp specimen preserved in ethanol \\
KA15.2 & Monascus sp. & 1994 & Shrimp specimen preserved in ethanol \\
KA15.3 & Monascus sp. & 1994 & Shrimp specimen preserved in ethanol \\
KA30.1 & Monascus sp. & 1994 & Shrimp specimen preserved in ethanol \\
KA30.2 & Monascus sp. & 1994 & Shrimp specimen preserved in ethanol \\
KA30.3 & Monascus $\mathrm{sp}$. & 1994 & Shrimp specimen preserved in ethanol \\
KA70.1 & Monascus sp. & 1994 & Shrimp specimen preserved in ethanol \\
\hline
\end{tabular}


BIOTROPIA VOL. 15 NO. 1, 2008

Table 1. Continued

\begin{tabular}{clcc}
\hline Strain Code & Fungus Name & $\begin{array}{c}\text { Year Cultured } \\
\text { \& Stored }\end{array}$ & Source of Strains \\
\hline KA70.3 & Monascus sp. & 1994 & Shrimp specimen preserved in ethanol \\
KA70.4 & Monascus sp. & 1994 & Shrimp specimen preserved in ethanol \\
KA70.4 NR4 & Monascus sp. & 1995 & Shrimp specimen preserved in ethanol \\
KA70.5 & Monascus sp. & 1994 & Shrimp specimen preserved in ethanol \\
KTB & Monascus sp. & 1993 & Coelenterata specimen preserved in ethanol \\
MYOM & Monascus sp. & 1994 & Maibua fasciata specimen preserved in ethanol \\
MYOT & Monascus sp. & 1994 & Myotis ultisima specimen preserved in ethanol \\
NGK & M.purpureus & 1993 & Chinese red rice \\
\hline
\end{tabular}

\section{RESULTS AND DISCUSSION}

After pre-treated by soaking in sterile water for three hours and subsequently re- cultivated on new fresh agar medium, 17 drying Monascus cultures successfully recovered. One culture was contaminated by bacteria, three were contaminated by molds (Aspergillus and Penicillium), and 13 cultures were in pure condition (Table 2).

Recovery capability (Table 2) indicated that 15 cultures were in good and the other two in bad condition. However, poor growth of these two cultures might be affected by the growth of the contaminant. After purification (Table 4) these cultures could grow well. All Monascus growth could be observed after three days incubation at room temperature $\left(25-31^{\circ} \mathrm{C}\right)$.

The purpose of purification work was to get rid of bacterial contamination from culture with code strain MYOT, by re-cultivation the Monascus colony on water agar medium and the other four Monascus such as $M$. purpureus SRB6.1, M. purpureus SLC, $M$. purpureus MLGB, and $M$. purpureus BDG 2.1 as well (Table 3). Those four cultures were also known to suffer from bacterial contamination. This additional work was intended to enrich the data. The result indicated that this purification was much possible since the bacteria grew very restricted, but Monascus grew rapidly leaving bacterial colony. After isolation and re-cultivation on the new medium this Monascus colony grew well (Table 3).

As the three Monascus cultures were contaminated by other molds, purification attempt was carried out using ethanol-soaking treatment before its cultivation on agar medium. This technique could eliminate mold contamination from the three cultures (Table 4). However, this technique did not work for bacterial contamination. The purification of culture with code strain MYOT contaminated by bacteria could not be carried out, as the bacteria were not effectively inhibited by ethanol. Therefore, this technique can be used for purification from fungal contamination. 
After pre-treated by one minute-ethanol (70\% or $95 \%)$ soaking on Monascus drying cultures before cultivation on MEA $2 \%$ showed that all cultures could grow well (Table 5). Visually, there was obviously no effect on the Monascus growth. Figure 1 shows the growth of Monascus sp. A70.4 on MEA 2\%. Without pre-treated by soaking in ethanol, the fungal contaminant grew well and no growth of the Monascus was observed when this contaminated culture was cultivated in MEA 2\%. When this contaminated culture was pre-treated by soaking in ethanol at $70 \%$ or $95 \%$, the Monascus culture grew well and there was no growth of fungal contaminant observed. Therefore, this treatment enables to purify Monascus cultures from fungal contamination. Hence, it is recommended to use this simple technique to deal with fungal contamination of Monascus cultures especially $M$. purpureus, $M$. ruber or maybe other osmophilic Monascus.

Observation under light microscope of all Monascus strains indicated that all strains still produced ascomata abundantly, ascospores and aleuriospores (Table 6). The color of Monascus colony was whitish shade, except NGK strain was blood red. Based on these results, at least drying more than 10 years did not change the above characters observed.

Cultivation in $20 \%$ ethanol medium showed that 11 Monascus strains were able to grow but not the other nine strains (Figure 2). The growth of these 11 strains was observed at various days (7-12 days) of incubation on PGY ethanol 20\% (Table 6). This treatment aimed at the capability of growing Monascus strains in ethanol at extreme concentration showed that the 11 strains which originated from degraded ethanol still retained their viability.

Table 2. Recovery of Monascus drying culture after 10 years of storage.

\begin{tabular}{cccc}
\hline Strain Code & Viability & Purity & $\begin{array}{c}\text { Recovery Capability } \\
\text { (Colony Growth) }\end{array}$ \\
\hline A70.1.2 & Viable & Pure & Good \\
COEL & Viable & Pure & Good \\
KA15.1 $(\mathrm{I})$ & Viable & Pure & Good \\
KA15.2 & Viable & Pure & Good \\
KA15.3 & Viable & Pure & Good \\
KA30.1 & Viable & Pure & Good \\
KA30.2 & Viable & Contaminated by Aspergil- & Good \\
KA30.3 & Viable & lus (overgrowth) & Good \\
KA70.1 & Viable & Pure & Good \\
KA70.3 & Viable & Pure & Good \\
KA70.4 & Viable & Contaminated by Penicil- & Good \\
\hline
\end{tabular}


BIOTROPIA VOL.15 NO. 1, 2008

Table 2. Continued

\begin{tabular}{cccc}
\hline Strain Code & Viability & Purity & $\begin{array}{c}\text { Recovery Capability } \\
\text { (Colony Growth) }\end{array}$ \\
\hline KA70.4 NR4 & Viable & Pure & Good \\
KA70.5 & Viable & $\begin{array}{c}\text { Contaminated by Asper- } \\
\text { gillus (overgrowth) }\end{array}$ & Poor \\
KTB & Viable & Pure & Good \\
MYOM & Viable & Pure & Good \\
MYOT & Viable & $\begin{array}{c}\text { Contaminated by bacteria } \\
\text { (overgrowth) }\end{array}$ & Poor \\
NGK & Viable & Pure & Good \\
\hline
\end{tabular}

Table 3. Recultivation of Monascus colony contaminated by bacteria.

\begin{tabular}{lcc}
\hline \multirow{2}{*}{ Strain Code } & \multicolumn{2}{c}{ Growth (3 days old) } \\
\cline { 2 - 3 } & MEA 2\% & WA \\
\hline Monascus sp. MYOT & $\mathrm{M}$ & $\mathrm{R}$ \\
M. purpureus SRB6.1 & $\mathrm{M}$ & $\mathrm{R}$ \\
$M$. purpureus SLC & $\mathrm{M}$ & $\mathrm{R}$ \\
$M$. purpureus MLGB & $\mathrm{M}$ & $\mathrm{R}$ \\
$M$. purpureus BDG 2.1 & $\mathrm{M}$ & $\mathrm{R}$ \\
\hline
\end{tabular}

Notes :

M: Bacterial and Monascus growth mixed; direct Monascus isolation was not possible.

R: Bacterial growth was very restricted, direct Monascus isolation was possible.

Table 4. Purification from fungal contamination using Ethanol-Soaking Treatment

\begin{tabular}{cccc}
\hline \multirow{3}{*}{ Strain Code } & \multicolumn{3}{c}{ Ethanol Treatment } \\
\cline { 2 - 4 } & \multicolumn{3}{c}{ Go\% } \\
\cline { 2 - 4 } & Poor, Aspergillus & Good, Pure & Good, Pure \\
\hline KA30.2 & Poor, Penicillium & Good, Pure & Good, Pure \\
KA70.4 & Poor, Aspergillus & Good, Pure & Good, Pure \\
KA70.5 & Poor, Bacteria & Poor, Bacterial contami- & Poor, Bacterial contamina- \\
MYOT & & nation & tion \\
& & &
\end{tabular}


Recovery of more than 10 years-drying Monascus culture - Nandang Suharna.

Table 5. The Effect of 1 minute-ethanol soaking treatment on Monascus grown on Malt Extract Agar $2 \%$ after three days incubation at room temperature.

\begin{tabular}{|c|c|c|c|}
\hline \multirow{2}{*}{ Strain Code } & \multicolumn{3}{|c|}{ Ethanol Concentration } \\
\hline & $0 \%$ & $70 \%$ & $95 \%$ \\
\hline Monascus sp. A70.1.2 & + & + & + \\
\hline Monascus sp. COEL & + & + & + \\
\hline Monascus sp. KA15.1 (I) & + & + & + \\
\hline Monascus sp. KA15.2 & + & + & + \\
\hline Monascus sp. KA15.3 & + & + & + \\
\hline Monascus sp. KA30.1 & + & + & + \\
\hline Monascus sp. KA30.2 & + & + & + \\
\hline Monascus sp. KA30.3 & + & + & + \\
\hline Monascus sp. KA70.1 & + & + & + \\
\hline Monascus sp. KA70.3 & + & + & + \\
\hline Monascus sp. KA70.4 & + & + & + \\
\hline Monascus sp. KA70.4 NR4 & + & + & + \\
\hline Monascus sp. KA70.5 & + & + & + \\
\hline Monascus sp. KTB & + & + & + \\
\hline Monascus sp. MYOM & + & + & + \\
\hline Monascus sp. MYOT & + & + & + \\
\hline M. purpureus NGK & + & + & + \\
\hline
\end{tabular}

Note :

$+=$ Good growth

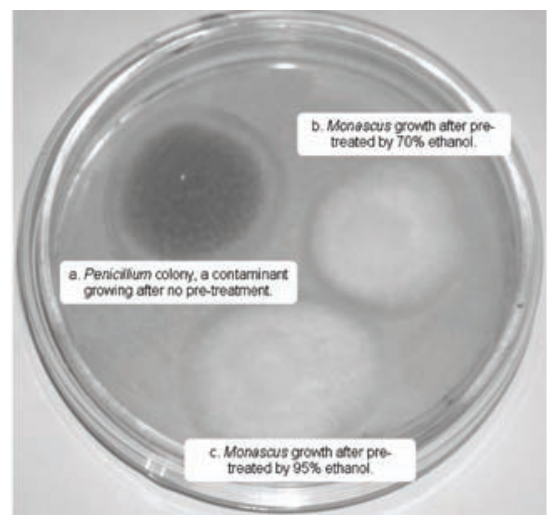

Figure 1. Monascus sp. A70.4 pre-treatment with and without soaking in ethanol for one minute before cultivation on MEA 2\% and incubated for 7 days at room temperature. The green colony is Penicillium growing from inoculation point of Monascus without pre-treatment; no Monascus colony observed (a). Two whitish colonies are Monascus, no fungal contaminant colony observed after the pre-treatment (the upper right was pre-treated by $70 \%$ ethanol) (b); below one was pre-treated by $95 \%$ ethanol (c). 
The above test obviously showed good stability of the drying Monascus cultures after ten years storage at room temperature, although from the growth tests in 20\% ethanol only $55 \%$ were able to grow well (Table 6). Figure 2 shows 5 Monascus strains growing well in $20 \%$ ethanol medium.

This study clearly showed that all drying Monascus cultures over 10 years could recover well and still retained its production of ascomata, ascospores and aleurispores, but not all Monascus tested including one $M$. purpureus strain showed its capability to grow in liquid medium containing ethanol at high concentration.

Table 6. The Retained Cultural and Morphological Properties of Monascus Drying Cultures and Their Resistance to 20\% Ethanol after Stored More Than 10 Years.

\begin{tabular}{|c|c|c|c|c|c|c|}
\hline \multirow{3}{*}{ Strain Code } & \multicolumn{5}{|c|}{$\begin{array}{l}\text { Growth on MEA 2\% } \\
\text { (Room temperature) }\end{array}$} & \multirow{3}{*}{$\begin{array}{c}\text { Grown on PGY Etha- } \\
\text { nol } 20 \% \\
\text { (Room temperature) } \\
\begin{array}{c}\text { Recovery } \\
\text { (day) }\end{array}\end{array}$} \\
\hline & \multirow{2}{*}{$\begin{array}{l}\text { Recovery } \\
\quad \text { (day) }\end{array}$} & \multicolumn{3}{|c|}{ Production } & \multirow{2}{*}{$\begin{array}{c}\text { Colony } \\
\text { Pigmentatiom }\end{array}$} & \\
\hline & & ASCMT & ASCPR & ALEU & & \\
\hline A70.1.1 & 3 & + & + & + & White yellowish & 7 \\
\hline A70.1.2 & 3 & + & + & + & White yellowish & No growth \\
\hline COEL & 3 & + & + & + & White yellowish & 10 \\
\hline KA15.1 & 3 & + & + & + & White yellowish & No growth \\
\hline KA15.2 & 3 & + & + & + & White yellowish & No growth \\
\hline KA15.3 & 3 & + & + & + & White yellowish & 10 \\
\hline KA30.1 & 3 & + & + & + & White yellowish & 10 \\
\hline KA30.2 & 3 & + & + & + & White yellowish & 10 \\
\hline KA30.3 & 3 & + & + & + & White yellowish & No growth \\
\hline KA70.1 & 3 & + & + & + & White yellowish & No growth \\
\hline KA70.3 & 3 & + & + & + & White yellowish & 7 \\
\hline KA70.4 & 3 & + & + & + & White yellowish & 7 \\
\hline $\begin{array}{c}\text { KA70.4 } \\
\text { NR4 }\end{array}$ & 3 & + & + & + & White yellowish & No growth \\
\hline KA70.5 & 3 & + & + & + & White yellowish & No growth \\
\hline KNS15.1 & 3 & + & + & + & White yellowish & 10 \\
\hline KTB & 3 & + & + & + & $\begin{array}{c}\text { White reddish } \\
\text { orange }\end{array}$ & 12 \\
\hline MM & 3 & + & + & + & $\begin{array}{c}\text { White reddish } \\
\text { orange }\end{array}$ & No growth \\
\hline MYOM & 3 & + & + & + & White yellowish & 10 \\
\hline MYOT & 3 & + & + & + & White yellowish & 12 \\
\hline NGK & 3 & + & + & + & Red Blood & No growth \\
\hline
\end{tabular}

Note :

ASCMT $=$ Ascomata, $\mathrm{ASCPR}=$ Ascospores, $\mathrm{ALEU}=$ Aleurispores,$+=$ Good production 


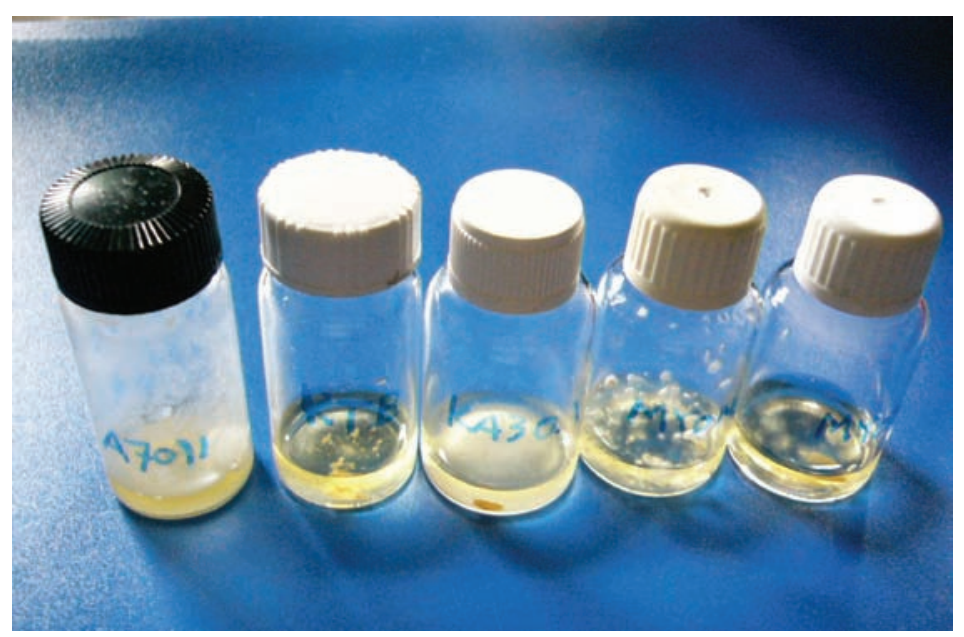

Figure 2. Five Monascus strains show its growth in liquid medium containing ethanol $20 \%$ after incubated for two weeks at room temperature. The growth indicated that the five Monascus strains still have the capability to grow in medium containing alcohol at very high concentration.

Good recovery of Monascus after 10 years storage in dry condition is in fact caused by the presence of ascospores produced by Monascus. These ascospores can germinate rapidly after one-day incubation period (Suharna 1999). Furthermore, these typical spores are abundantly produced (Hawksworth and Pitt. 1983; Suharna 1999). Without these spores, particularly M. purpureus, the fungus cannot survive in dry condition for years. We ever came across with failure of one drying collection of $M$. purpureus to grow after incubation for 5 years because of lacking of ascospores. This fact showed that the presence of ascospores is very vital for Monascus survival in dry condition for long time.

The result showed that all drying Monascus cultures for 10 years could recover well with $100 \%$ viability. However, without prior treatment by soaking in water for three hours before cultivation these recoveries would not succeed. It is known that Monascus is commonly found in substrate with low water activity. The Monascus collection tested here originated from dry substrate. Twenty Monascus isolates were isolated from deteriorated ethanol. This indicated that the 20 isolates were typical fungi with their survival capability in dry condition.

This result indicated important information at least an alternative for the maintenance of Monascus not only cheap and simple but also long-term storage (10 years) in particular. Therefore, it is recommended to use this method for the maintenance of $M$. purpureus or $M$. rubber in fermentation industry.

It is well known that one of the very simple methods to preserve mold is to use agar medium which comprises serial sub-culturing from poor medium to rich medium. 
The use of medium depended on the fungal strain (Smith 1993; Smith and Onion 1994). These methods need routine maintenance because the fungal cultures could only be stored for a short-term period before subculture. This storage period ought to be taken into account in maintaining fungal cultures to avoid late handling causing the death of the cultures. Several molds are known having its storage period between 2 and 4 weeks before sub-culturing. Whereas, the majority of fungi have the storage period between 2 and 4 months before re-cultured and others can be maintained until 12 months (Smith 1993; Smith and Onion 1994). Therefore, preservation method using agar causes routine maintenance and take much time.

During storage cultures kept on agar slope usually underwent drying because of evaporation. The nutrient content of the medium is already low and the fungal growth of cultures is in late phase (linear phase). In this condition most microbes including bacteria and fungi usually produce resistant spores. These spores are engineered for survival of its life. It is suggested that this kind of spores can survive for tens or hundreds or may be thousands years under dry condition.

Drying cultures can also be obtained by letting cultures kept on agar medium to dry in room temperatures. Monascus purpureus cultures kept on slope agar will dry quickly several weeks at room temperature. During its growth this fungus produces ascospores masses abundantly. This typical spore has a great function for survival of its life. This spore can survive from agony condition such as very low nutrient or drought of water.

However, it is of interest using more Monascus species in this study to know recovery capability of the Monascus originated from wet habitat such as M. sanguneus and $M$. pallens from dry condition compared to the other Monascus species which originated from dry habitat such as $M$. purpureus and M. rubber. Monascus sanguneus and $M$. pallens were firstly described by Cannon et al. (1995). These 2 species were isolated from the surface sediment of a river in Iraq and showed a non-osmophilic nature (Cannon et al. (1995). Most Monascus species are showing osmophilic affinity (Pitt \& Hocking 1997).

\section{CONCLUSIONS}

Ten-year drying cultures of 20 Monascus strains were well recovered (the viability is $100 \%$ ) with good retained characters such as growth, pigmentation and production of ascomata, ascospores and aleurispores. The capability to grow in alcohol at high concentration was shown by $60 \%$ of Monascus strains.

The purification method from fungal contamination by soaking in ethanol $70 \%$ or $95 \%$ was successfully effective.

The study on Monascus species showed long survival in dried agar medium, while there was no change in their cultural and morphological characteristics. 


\section{REFERENCES}

Cannon, P.F., S.K. Abdullah, and B.A. Abbas. 1995. Two New Species of Monascus from Iraq, with a Key to Known Species of the Genus. Mycol. Res., 99(6): 659662

Endo, A. 1979. Monacolin K; A New hypocholererolemic agent produced by a Monascus species. J. Antibiotic, 32(8), 852-854)

Hawksworth, D.L. and J.I. Pitt. 1983. A New Taxonomy for Monascus Species Based on Cultural and Microscopical Characters. Aust. J. Bot., 31:51 61

Nakasone KK, SW. Peterson, and S Jong, 2004 Preservation and Distribution of Fungal Cultures in Biodiversity of Fungi: Inventory and monitoring Methods.. Elsevier Academic Press, Amsterdam. p: $37-47$

Pitt JI, Hocking AD, 1997. Fungi and Food Spoilage. $2^{\text {nd }}$ Ed. Balnckie Academic \& Professional, London, United Kingdom

Saono S., I. Gandjar, T. Basuki, and H. Karsono. 1969. Mycoflora of Ragi and Some Other Traditional Fermented Food of Indonesia Annales Bogorienses 5, Part IV : 187204

Smith D. 1993. Notes on The Preservation of Fungi for Small Culture Collections. International Mycological Institute. Egham, Surrey, United Kingdom. 36 p.

Smith D. and A.H.S. Onions. 1994. The Preservation and Maintenance of Living Fungi. IMI Technical Handbooks No.2. International Mycological Institute. Egham, Surrey, United Kingdom. 120 p.

Steinkraus, K.H. 1983. Handbook of Indigenous Fermented Foods. Marcel Dekker, Inc. New York : 547 553

Stchigel AM, JF Canon, SK Abdullah and J Guarro. 2004. New and Interesting Species of Monascus From Soil, With A Key to The Known Species. Studies in Mycology 50: 299-306

Suharna N.1999. Pengaruh Perendaman di dalam Air sebelum Pemindahan Terhadap Pemulihan Biak-Biak Monascus spp. yang Mengering. Jurnal Mikrobiologi Tropika, 74 - 80

Watanabe, T. 2004. Personal Communication. 